特 集

\title{
進化し続ける自動車衝突シミュレータ
}

\section{Car Crash Simulators Continue to Make Progress}

\author{
三菱重工機械システム株式会社
}

Mitsubishi Heavy Industries Machinery Systems, Ltd.

\begin{abstract}
A car crash simulator is a test device that can accurately reproduce the acceleration generated in a vehicle cabin at the time of a car crash. They are used in the research and development of passive safety devices such as seats and seatbelts, air bags and headrests, doors, car interiors, etc.

This article describes the achievements made so far and future efforts for the car crash simulator that Mitsubishi Heavy Industries Machinery Systems, Ltd. manufactures and sells.

Keywords: car crash simulator, passive safety, servo actuator, collision safety.
\end{abstract}

\section{1 緒言}

世界各国では，発生した多数の交通事故の衝突形 態・乗員の障害状況を踏まえて, 事故の再現性を考慮

した各種実車衝突試験が実施されている。

実車衝突試験では完成車を毎回衝突させて破壊す るが，弊社の自動車衝突シミュレータは，車を破壊す ることなく自動車衝突時に客室に発生する加速度を精 度良く再現することができる試験装置であり，シート やシートベルト，エアバッグ，ヘッドレスト等のパッ シブセーフティー装置やドアや車内インテリア等の研 究・開発に利用される[1,2]。

本稿では，弊社シミュレータのこれまでの実績と今 後の取り組みについて紹介する。

\section{2 特長と主仕様}

弊社シミュレータは電気油圧サーボ方式を採用し た試験装置である。Fig. 1 亿装置の全景を示す。

試験の原理としては, Fig. 2 に示すように, 試験体を 搭載した台車をサーボアクチュエータのピストンで衝 突方向とは逆向きに打ち出すことで衝突加速度を発生 させる方式であり，現在主流の試験方法である。サー ボアクチュエータは，アキュムレータの蓄圧油を動力 源とし，台車上の加速度を目標加速度に一致させる

\footnotetext{
連絡先：三菱重工機械システム(株), 油圧・ゴムタイヤ機 械営業部, 一般機械営業課, $\bar{T} 652-8585$ 神戸市兵庫区和田 崎町 1-1-1, 三菱重工業(株)神戸造船所内 E ビル 2 階
}

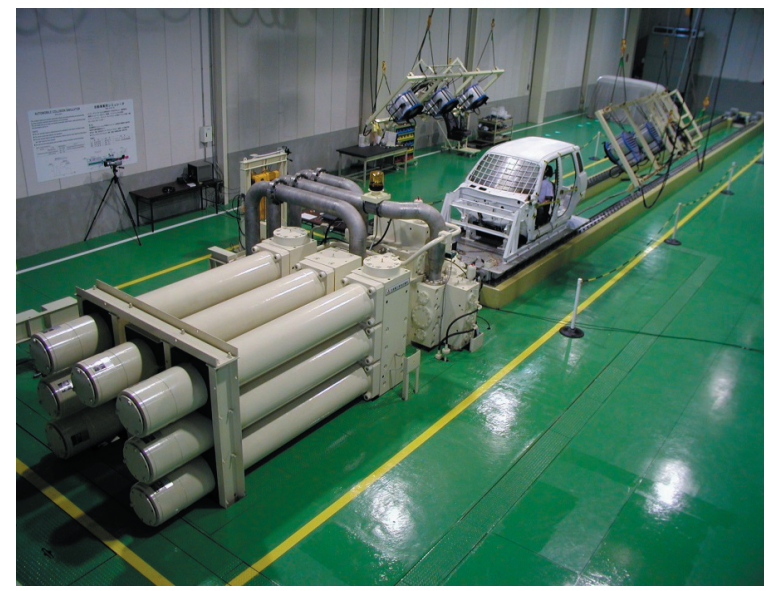

Fig. 1 Whole view of car crash simulator.

ようサーボ弁にて制御する。本システムの主仕様を Table 1 に示す。

弊社サーボアクチュエータの最大の特長は, サーボ 弁を作動油の排出側に配置したメータアウト方式を採 用していることである。これによりシリンダ内の高圧 始動を可能とし, 油圧加振系の固有振動数が上がるこ とで，衝突加速度波形を高周波成分まで忠実に再現す ることが可能となった。

また, サーボ弁を 9 台並列運転とし, 試験加速度の 大きさに応じてサーボ弁の運転台数を切り替えること で, 高加速度の前面衝突から低加速度の後面衝突まで 幅広い加速度範囲の衝突試験を可能としている。

加えて，ピストンを両ロッドとすることで打出し前 のピストン移動を防止し, ピストン動き出しタイミン グの精度を向上させている。このことは，エアバック やシートベルトの作動タイミング調整試験において重 
要な要件となっている。

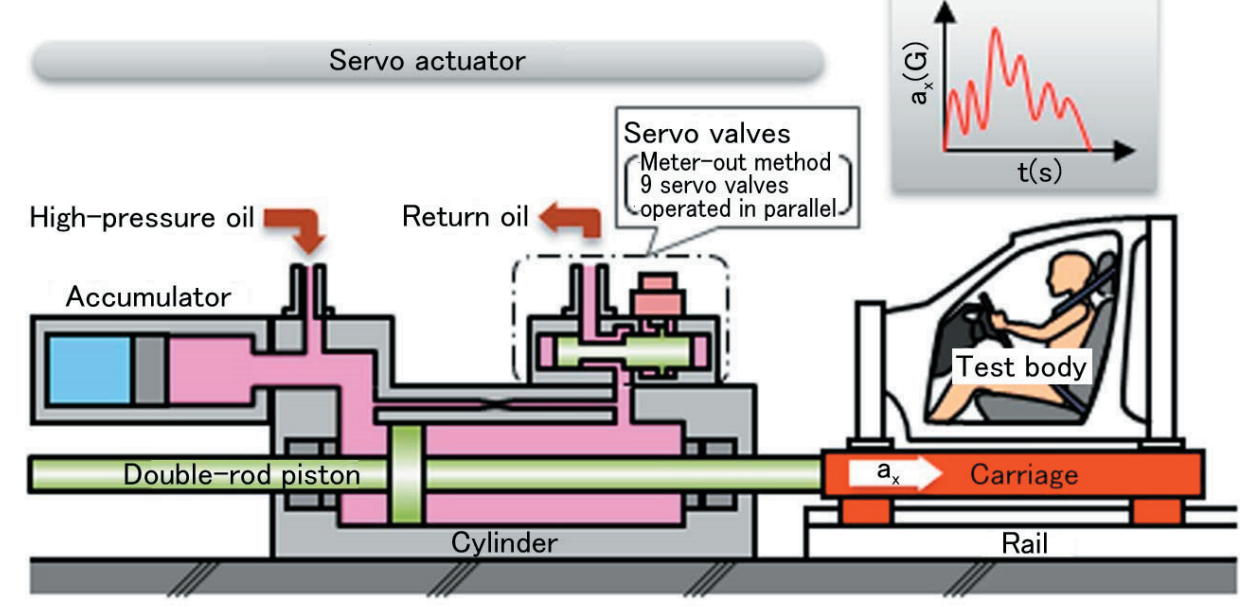

Fig. 2 System overview.

Table 1 Example of main specifications.

\begin{tabular}{|l|l|l|}
\hline \multicolumn{1}{|c|}{ Item } & \multicolumn{1}{|c|}{ Specification value } & \multicolumn{1}{c|}{ Remark } \\
\hline Mass of test body & $2,000 \mathrm{~kg}$ at maximum & \\
\hline Firing acceleration & $80 \mathrm{G}$ at maximum & With a test body of $1,500 \mathrm{~kg}$ \\
\hline Firing velocity & $90 \mathrm{~km} / \mathrm{h}$ at maximum & $=25 \mathrm{~m} / \mathrm{s}$ \\
\hline Control displacement & $1,700 \mathrm{~mm}$ at maximum & $=$ Piston stroke \\
\hline Control time & $0.3 \mathrm{~s}$ at maximum & \\
\hline Response frequency & $150 \mathrm{~Hz}$ at maximum & \\
\hline
\end{tabular}

Table 2 Process of progress of basic performance.

\begin{tabular}{|c|c|c|c|c|c|c|c|c|c|c|c|c|c|c|c|c|c|}
\hline Basic performance & 1997 & 1998 & 1999 & 2000 & 2001 & 2002 & 2003 & 2004 & 2005 & 2006 & 2007 & 2008 & 2009 & 2010 & $\sim$ & 2016 & 2017- \\
\hline Mass of test body & $700 \mathrm{~kg}$ & & & $1,300 \mathrm{k}$ & $g \rightarrow$ & $1,500 \mathrm{k}$ & & & & $\rightarrow$ & $2,000 \mathrm{k}$ & & & & & & \\
\hline Firing acceleration & $40 \mathrm{G}$ & & & $75 \mathrm{G}$ & & & & & & & $\rightarrow$ & $80 \mathrm{G}$ & & & & & $\begin{array}{l}90 \mathrm{G} \\
\text { (Under } \\
\text { development) }\end{array}$ \\
\hline Firing velocity & $65 \mathrm{~km} / \mathrm{h}$ & h & & $83 \mathrm{~km} /$ & & $\longrightarrow$ & $90 \mathrm{~km} / \mathrm{h}$ & & & & & & & & & & \\
\hline Control displacement & $1,000 \mathrm{~m}$ & $\mathrm{hm}$ & & $\begin{array}{c}1,300 \mathrm{~m} \\
\mathrm{~L}\end{array}$ & $\stackrel{\mathrm{m}}{\longrightarrow}$ & $\underset{1,500 \mathrm{n}}{\longrightarrow}$ & $\begin{array}{l}1,700 \mathrm{~h} \\
\mathrm{hm}\end{array}$ & $\mathrm{nm}-$ & & & & & & & & & \begin{tabular}{|l|}
$2,200 \mathrm{~mm}$ \\
(Being \\
manufactured)
\end{tabular} \\
\hline $\begin{array}{l}\text { Control } \\
\text { time }\end{array}$ & $0.12 \mathrm{~s}$ & & & $0.15 \mathrm{~s}$ & & $0.3 \mathrm{~s}$ & & & & & & & & & & & $\begin{array}{l}0.6 \mathrm{~s} \\
\text { (Being } \\
\text { manufactured) }\end{array}$ \\
\hline Response frequency & $80 \mathrm{~Hz}$ & & & $100 \mathrm{~Hz}$ & $\rightarrow$ & $150 \mathrm{~Hz}$ & & & & & & & & & & & \begin{tabular}{|l|}
$160 \mathrm{~Hz}$ \\
(Being \\
manufactured) \\
\end{tabular} \\
\hline Our deliveries & OFi & rst moc & & ^ & $\begin{array}{c}0 \\
\text { Meter- }\end{array}$ & $\begin{array}{c}0 \\
\text { but met }\end{array}$ & $\begin{array}{c}0 \\
\text { hod ado }\end{array}$ & & ? & & 0 & 8 & & 8 & 8 & O & $\begin{array}{l}\text { (Being } \\
\text { manufactured) }\end{array}$ \\
\hline
\end{tabular}


Table 3 Collision safety standards and the history of the introduction of new car assessment testing (example in Japan).

\begin{tabular}{|c|c|c|c|c|c|c|c|c|c|c|c|c|c|c|c|c|c|}
\hline \multicolumn{2}{|c|}{ Test item } & 1994 & 1995 & $\sim$ & 1998 & 1999 & 2000 & 2001 & $\sim$ & 2006 & 2007 & 2008 & 2009 & $\sim$ & 2014 & $\sim$ & 2017 \\
\hline \multirow{8}{*}{ Collision safety } & Full-wrap frontal & & & & & & & & & & & & & & & & \\
\hline & & & & & & & & & & & & & & & & & \\
\hline & Offset frontal & & & & & & & & & & & & & & & & \\
\hline & & & & & & & & & & & & & & & & & \\
\hline & Side collision & & & & & & & & & & & & & & & & \\
\hline & Rearend collicion & & & & & & & & & & & & & & & & \\
\hline & $\begin{array}{l}\text { neck injury } \\
\text { protection }\end{array}$ & & & & & & & & & & & & & & & & \\
\hline & Child car seat & & & & & & & & & & & & & & & & \\
\hline Active safety & $\begin{array}{l}\text { Collision damage } \\
\text { reducing brake }\end{array}$ & & & & & & & & & & & (Aga & inst v & hicle & & & \\
\hline
\end{tabular}

Table 4 Representative test options.

\begin{tabular}{c|l|l}
\hline Test option & \multicolumn{1}{|c|}{ Description } & \multicolumn{1}{c}{ Remarks } \\
\hline Pitching & $\begin{array}{l}\text { Purpose: To improve the accuracy of frontal collision tests } \\
\text { Content: Reproducing vehicle movements in the up-and-down } \\
\text { direction and vertical rotation at the time of a frontal collision }\end{array}$ & $\begin{array}{l}\text { Addition of four vertical } \\
\text { actuators and special } \\
\text { carriage }\end{array}$ \\
\hline Soe board intrusion & $\begin{array}{l}\text { Purpose: To improve the accuracy of frontal collision tests } \\
\text { Content: Reproducing the phenomenon of toe board intrusion into } \\
\text { the cabin }\end{array}$ & $\begin{array}{l}\text { Two degrees of freedom } \\
\text { motions of parallel } \\
\text { movement and inclining }\end{array}$ \\
\hline Rear-end collision & $\begin{array}{l}\text { Purpose: To reproduce a side collision test } \\
\text { Content: Making doors collide with passenger dummies while } \\
\text { door's accelerating and decelerating }\end{array}$ & $\begin{array}{l}\text { Addition of carriage and jigs } \\
\text { for side collision test } \\
\text { protection performance tests } \\
\text { by variable control of the number of servo valves }\end{array}$ \\
\hline
\end{tabular}

Table 5 Development history and deliveries for the representative test options.

\begin{tabular}{|c|c|c|c|c|c|c|c|c|c|c|c|c|c|c|c|}
\hline Test option & 1997 & $\sim$ & 2002 & 2003 & 2004 & 2005 & 2006 & 2007 & 2008 & 2009 & 2010 & 2011 & $\sim$ & 2016 & $2017 \sim$ \\
\hline Pitching & & & & & & O & & O & & & 8 & & & & $\begin{array}{l}\text { (Being } \\
\text { manufactured) }\end{array}$ \\
\hline Toe board intrusion & & & & & & & & & & & & & & & \\
\hline Side collision & $\oslash$ & & $\oslash$ & $\oslash$ & & & & $\otimes$ & $\oslash$ & & $\oslash$ & 0 & & $\oslash$ & \\
\hline Rear-end collision & & & $\mathscr{B}$ & & & Here & ffter, & quippe & 1 as sta & hdard. & & & & & \\
\hline
\end{tabular}

電気油圧サーボアクチュエータの制御方式として は開ループを採用し，試験体の加速度を目標加速度に
一致させるために, 加振系の詳細なモデルを用いた改 善演算機能を有している[1,2]。 


\section{3 基本性能向上への取り組み}

弊社は 1997 年に初号機を市場投入して以来，基本 性能の向上に取り組んできた。自動車衝突現象をより 忠実に再現するために求められる基本性能の主な方向 は, 大パワー (試験体質量 $\times$ 加速度, 速度), 大変位, 高応答であって, これらの項目の進化過程を Table 2 に 示す[1]。

さらに，負荷質量を小さくするため，試験体を搭載 する台車はアルミ合金や高張力鋼を積極的に採用して いる。

\section{4 試験オプション開発への取り組み}

車両技術や技術的知見の向上により，新たな衝突安 全性試験が導入されてきており, Table 3 は日本におけ る安全基準と自動車アセスメントの試験導入の歴史で ある $[3,4]$ このような試験動向に対応するため, 弊社 は様々な試験オプションの開発に取り組んできた。代 表的な試験オプションを Table 4 に, その開発履歴と納 入実績を Table 5 に示しており, 世界の試験動向を先取 りした試験オプションを開発し，市場投入を実現して いる[1]。
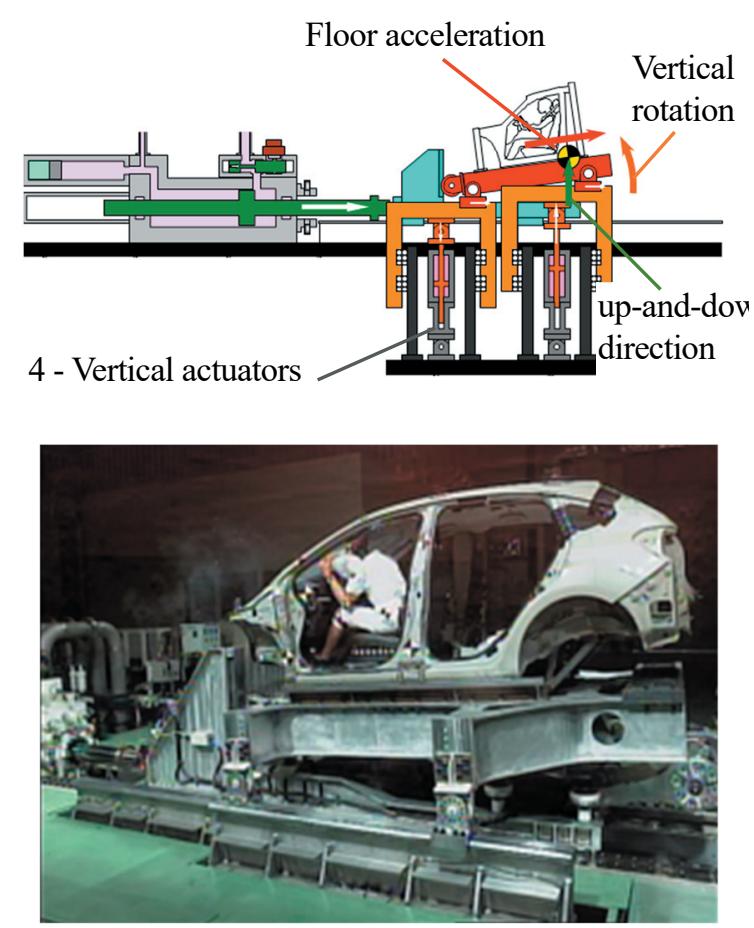

Fig. 3 Pitching test option.
その中で最も大規模な試験オプションはピッチン グであって，4 本の鉛直サーボアクチュエータを追設 することで, 車両の前後方向に加え, Fig. 3 に示すよう な上下方向・上下回転の 3 自由度運動が可能となる。 これにより，前面衝突試験がより忠実に再現できるよ うになった。

またトーボードイントルージョンオプションは，衝 突時に室内側に侵入してくる前席足元の車体パネル挙 動を再現し，乗員ダミー下肢損傷を忠実に評価するた めの装置である[5]。

側面衝突オプションは, Fig. 4 に示すようにドアを サーボアクチュエータのピストンと自在継手で連結し， ドアをシートに座った乗員ダミーに向かって打ち出す ことで，車両側面から衝突されたときのドアの室内侵 入挙動を再現する装置である。

後面衝突オプションは, 自動車後部からの追突され た際の䡈部の保護性能を評価するための試験であり,

Fig. 5 に示すように乗員ダミーは前面衝突と逆向きに 搭載され打ち出される。ただし本試験の衝突波形は $10 \mathrm{G}, 18 \mathrm{~km} / \mathrm{h}$ 程度と前面衝突に比べ小さく, 小さな加 速度を精度良く再現するために，サーボアクチュエー 夕を駆動する複数台のサーボ弁を間引き運転すること が弊社の技術的な特徴である。
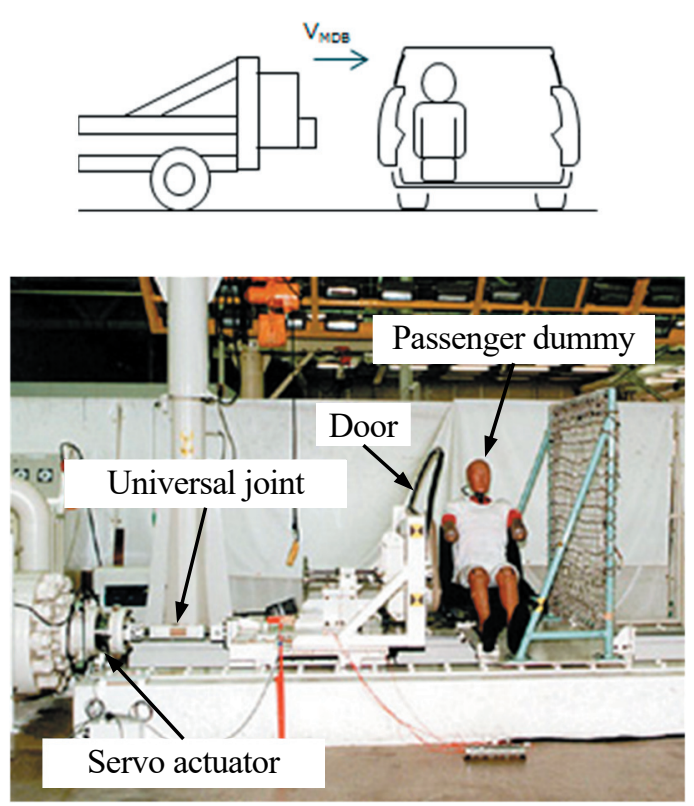

Fig. 4 Side collision option. 

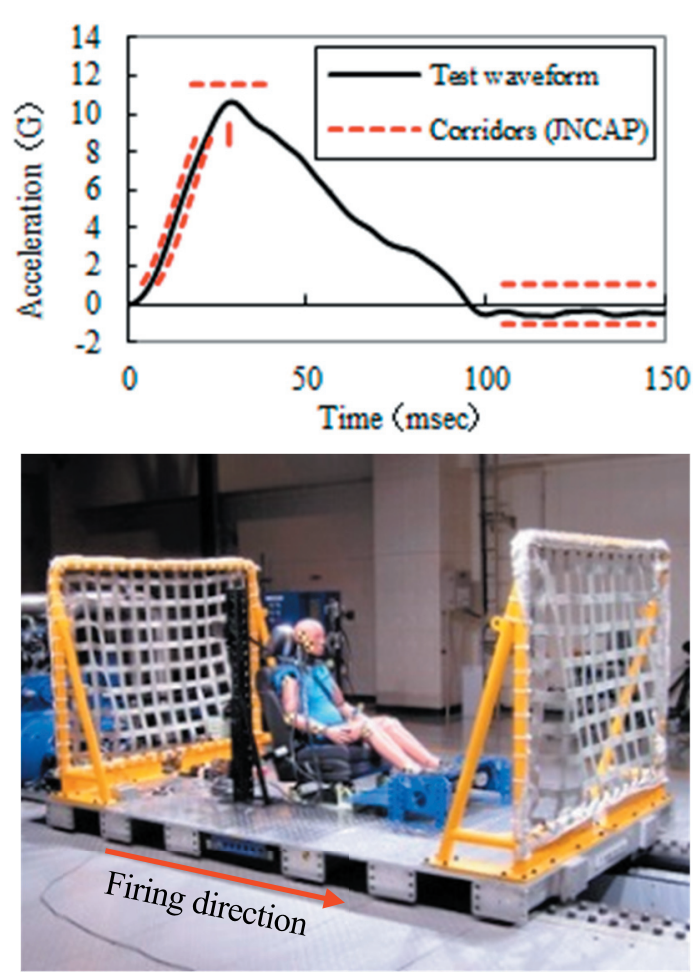

Fig. 5 Rear end collision option.

\section{5 新たな取り組み}

弊社が注目している世界の自動車衝突安全技術の 動向は，スモールオーバーラップ衝突試験（車両前面 $25 \%$ のバリア衝突）やオブリーク衝突試験 $(90 \mathrm{~km} / \mathrm{h}$ 斜 め $15 \mathrm{deg}$ 方向からの台車衝突）への対応や衝突被害軽 減ブレーキの普及, 自動運転車であり, これらに関連
して弊社シミュレータに要求される今後の開発目標を Table 6 のように考える。

今後開発す心゙き項目としては，車両の左右回転運動 を可能とするヨーイング装置や，衝突被害軽減ブレー キの加速度を再現するための長ストローク型アクチュ エータ，小型車両の衝突加速度を再現するための高加 速度対応アクチュエータや台車などが挙げられる[1]。

\section{6 結言}

自動車関連技術の発展に連動し, 求められる衝突安 全性能も時代と共に変化していくと考えられ，弊社は 世界中の新たな衝突安全性試験に対応すべく今後も果 敢に取り組んでいく所存である。

\section{参考文献}

[1] 三菱重工業株式会社，三菱重工技報，交通・輸送特集， Vol. 53, No. 3, pp. 34-36, 2016.

[2] 合木, 内田, 衝撃試験装置と油圧サーボ，油空圧技術, Vol. 43, No. 1, 2004.

[3] 自動車アセスメント衝突安全性能評価 事故時に人を守 る技術，独立行政法人自動車事故対策機構，pp. 36-37, 2016.3 .

[4] 独立行政法人自動車事故対策機構, http://www.nasva .go.jp/.

[5] 西村, 自動車の衝突安全, 安全工学, Vol. 48, No. 5, pp. 288-292, 2009.

Table 6 Future development targets.

\begin{tabular}{l|l|l}
\hline Trend in collision safety technology & \multicolumn{1}{|c}{ Development target } & \multicolumn{1}{c}{ Description } \\
\hline Small overlap and oblique test & Yawing device & $\begin{array}{l}\text { Reproducing the horizontal rotational movement of the } \\
\text { vehicle in a small overlap and oblique crash test }\end{array}$ \\
\hline Collision damage reducing brake & Prebrake-capable actuator & $\begin{array}{l}\text { An actuator that can simultaneously reproduce the } \\
\text { behaviors of a collision damage reducing brake and } \\
\text { collision acceleration }\end{array}$ \\
\hline Self-driving compact car & Actuator for compact car & $\begin{array}{l}\text { An actuator that can be operated for collision waveforms } \\
\text { typical in compact cars which are expected to spread as } \\
\text { self-driving cars, electric cars, etc. }\end{array}$ \\
\hline
\end{tabular}

